\title{
The change in the physicochemical composition of food products under the influence of gamma radiation with the dose of radiation used for bacterial disinfection
}

\begin{abstract}
Some aspects of radiation exposure. It is shown that the effect of $\gamma$-irradiation on the studied objects with a dose rate of $1-6 \mathrm{kGy}$ makes it possible to increase the shelflife, but lead to a substantial change in the chemical structure of the lipid part of the products, which requires the solution of the human consumption of such food.
\end{abstract}

Keywords: radiation exposure, fats, meat raw materials, food products, gamma irradiation
Volume 5 Issue I - 2018

\author{
Belyakov VA, Chernobrovina OK, Proshina \\ OP, Ivankin AN \\ Department of Chemistry, Bauman Moscow State Technical \\ University, Russia
}

\author{
Correspondence: Andrew N Ivankin, Department of \\ Chemistry, Bauman Moscow State Technical University, 105005, \\ Moscow, 2nd Bauman Str. 5, Moscow, Russia, \\ Email aivankin@inbox.ru
}

Received: December 13,2017 | Published: January 31, 2018

\section{Introduction}

Energy-physical impact on environmental objects for more than half a century is a constant interest in terms of the possibility of the beneficial use of the results of such effects on food systems. The most effective in achieving the final result is radiation exposure. The development of nuclear power has led to the appearance of relatively accessible sources of radiation exposure, which are used in chemistry, biotechnology, medicine and the food industry. For these purposes, three types of ionizing radiation are allowed

i. $\gamma$-irradiation by means of a so-called "cobalt gun" containing a radioactive isotope ${ }^{60} \mathrm{Co}$ with a half-life of about 5 years and an energy of $1.3 \mathrm{MeV}$ or an isotope ${ }^{137} \mathrm{Cs}$ (with energy $0,66 \mathrm{MeV}$ )

ii. Irradiation with $\mathrm{x}$-rays on installations with an energy of $5 \mathrm{MeV}$, and

iii. Exposure to electrons by electron accelerators with an energy of $10 \mathrm{MeV}^{1-3}$

Irradiation of food raw materials has a double effect. Firstly, actually for which the irradiation is carried out, destruction of microorganisms is provided to increase the shelf life of products. Secondly, radiation has a danger from the point of view of the effect on the raw materials and products based on it, causing chemical transformations of constituent components by the mechanism of radiolysis. ${ }^{4}$

The change in the chemical composition of the irradiated objects is undesirable, therefore, in the case of food systems, there are normative documents regulating the "safe" use of radiation. In the European Union, the requirements for the safety of radiation-processed foods are set out in Standard 106-1983, Rev.1-2003 and the Directive of the European Council and Parliament 1999/2/EC of 22.02.1999. Today, according to IAEA data, in 69 countries, there is a permit to irradiate more than 80 types of products. In 40 countries, primarily in China and the United States, irradiation of food products on an ongoing basis. $^{5}$

In the Soviet Union (Russia) from 1964-1967, a limited use of radiation exposure was allowed. These norms formally operate so far to suppress microorganisms and extend the shelf life of raw meat semi-finished products from beef, pork and rabbits packed in film (test batch) with a dose rate of 6-8kGy, gutted chicken, packed in film with a dose of $6 \mathrm{kGy}$, cooked meat products (roast meat, entrecote), packed in film (test batches) with an irradiation dose of $8 \mathrm{kGy}$. Investigation of the effects of different doses of radiation shows that the lethal doses of gamma irradiation for different microorganisms differ significantly. So the lethal dose at room temperature is (kGy): for Salm. typhimurium-3, E. coli, Str. faecalis, Shig dysenteriae-6, Micobac tuberculosis-10, Sarcina lutea, Bac. pumilus (spores)-17, Bac. sabtilis (spores), Clostr. sporogenes (spores), Aspergillus niveus-20, Clostr. botulinum-90.1,3 Those, for a full guaranteed disinfection of products, sufficiently high doses of radiation exposure are necessary.

High doses of radiation lead to the formation of new chemical components in irradiated objects. In particular, because of the high content of fats in irradiated to $10 \mathrm{kGy}$ products, 2-alkylcyclobutanone is often found, which is a product of radiochemical transformation of lipid components. This substance is not originally contained in meat raw materials and can be used as a marker of strong exposure to food products. ${ }^{6,7-9}$ Due to the fact that the overwhelming majority of products contain a significant amount of fat components, it was of interest to assess changes occurring during irradiation.

\section{Materials and methods}

As research objects used meat raw materials (longissimus dorsi beef, pork), minced meat from pork and beef (50:50) with a mass fraction of fat of $23.5 \%$ and boiled sausage products- sausage Milk 
(Russian Trademark). The irradiation was carried out on a RXM-y20 setup with a $\gamma$-radiation source of ${ }^{60} \mathrm{Co}$ at room temperature. The main physicochemical parameters were determined by standard methods. ${ }^{8}$ The presence of basic chemicals in irradiated products was studied by chromatographic mass spectrometry. To do this, a sample of $1 \mathrm{~g}$ of the sample was treated for 8 hours with a mixture of $12 \mathrm{ml}$ of chloroform with $10 \mathrm{ml}$ of methanol in the presence of $1 \% \mathrm{KCL}$ solution to dissolve the chemical components, the extract was filtered through paper. $1 \mathrm{ml}$ of an extract containing about $0.1 \mathrm{~g}$ of a dry residue was mixed with $5 \mathrm{ml}$ of a $15 \%$ solution of acetyl chloride in methanol, held for 2 hours at $100^{\circ} \mathrm{C}$ in a sealed glass ampoule in an Ar atmosphere and neutralized by the addition of us. Solution of $\mathrm{KOH}$ in $\mathrm{CH}_{3} \mathrm{OH}$ to a solution $\mathrm{pH}$ of 5.0-6.0. To the mixture was added $3 \mathrm{ml}$ of us. Aqueous $\mathrm{NaCl}$ solution and $6 \mathrm{ml}$ of hexane was left for 30 minutes and $0.5 \mathrm{ml}$ of a clear hexane layer containing methylated and unmethylated forms of the analytes was taken for analysis. HP-5MS capillary column chromatography conditions: carrier gas-He, flow rate $1 \mathrm{ml} / \mathrm{min}$, injector temperature in $250^{\circ} \mathrm{C}$ flow-divide mode, initial column thermostat temperature of $100^{\circ} \mathrm{C}$ for $2 \mathrm{~min}$, programmable heating from $100^{\circ} \mathrm{C}$ to $290^{\circ} \mathrm{C}$ at a speed of $20^{\circ} \mathrm{C} / \mathrm{min}$, isotherm at a temperature of $290^{\circ} \mathrm{C}$ up to $25 \mathrm{~min}$, the analysis time of the components is $25 \mathrm{~min}$, the volume of the automatically entered sample is $1 \mu$ l. Identification parameters: temperature of ion sources $230^{\circ} \mathrm{C}$, temperature of quadrupole $150^{\circ} \mathrm{C}$, electron energy $70 \mathrm{eV}$, detection in scanning mode of full mass spectrum in the mass range 33-1050a.m.u. For the calculation of the content of substances, an automated database for the search and identification of NIST08 MS Library chromatography-mass spectrometry data was used, with a peak-to-peak correlation probability of more than $65 \%$. The results of the determination were processed using mathematical statistics methods.

\section{Results and discussion}

In Table 1 presents some results of the determination of conventional physicochemical indicators of the quality of products based on meat raw materials. As can be seen from the presented data, the main physicochemical indicators of the safety and quality of meat raw materials and products based on it, as a result of radiation exposure at a selected dose of $1-3 \mathrm{kGy}$, changed insignificantly, remaining at the level of indicators usually observed for various types of similar products without radiation treatment. The selected irradiation range basically provides a certain level of antimicrobial treatment. This makes it possible to consider the shelf life of such products in the frozen state at $-20^{\circ} \mathrm{C}$ for $1-6$ months.

Table I Change in basic physicochemical parameters of meat and meat products subjected to $\gamma$-irradiation during storage at $-20^{\circ} \mathrm{C}(n=5)$

\begin{tabular}{|c|c|c|c|c|c|c|c|c|c|c|c|}
\hline $\begin{array}{l}\text { Name } \\
\text { product }\end{array}$ & $\begin{array}{l}\text { The dose of } \\
\text { irradiation, } \\
\text { kGy }\end{array}$ & $\begin{array}{l}\text { Shelf } \\
\text { Life, } \\
\text { Days }\end{array}$ & $\mathrm{pH}$ & $\begin{array}{l}\text { Moisture, } \\
\%\end{array}$ & $\begin{array}{l}\text { Content } \\
\text { of } \\
\text { sodium } \\
\text { nitrite, } \\
\%\end{array}$ & $\begin{array}{l}\text { Acid } \\
\text { number, } \\
\text { mg } \\
\mathrm{KOH} / \mathbf{g}\end{array}$ & $\begin{array}{l}\text { Peroxide } \\
\text { number, } \\
\text { mmol } \\
\text { act. } O_{2} I \\
\text { kg fat }\end{array}$ & $\begin{array}{l}\text { The } \\
\text { Content } \\
\text { of } \\
\text { volatile } \\
\text { fatty } \\
\text { acids, mg } \\
\text { KOH/25 } \\
\text { g }\end{array}$ & $\begin{array}{l}\text { Amino- } \\
\text { ammonia } \\
\text { nitrogen, } \\
\text { mg/l00 g }\end{array}$ & $\begin{array}{l}\text { Protein, } \\
\%\end{array}$ & Fat, \% \\
\hline \multirow{2}{*}{ Beef } & 0 & 0 & 6,12 & 75,92 & 0 & 1,03 & I,86 & 1,22 & 16,2 & 21,6 & 1,3 \\
\hline & 3 & 30 & 6,11 & 75,69 & 0 & $\mathrm{I}, 34$ & 1,05 & 1,68 & 15,9 & 21,5 & 1,3 \\
\hline \multirow{3}{*}{ Pork } & 0 & 0 & 5,98 & 76,21 & 0 & 1,12 & 2,04 & 1,36 & 18,0 & 20,5 & 2,2 \\
\hline & 3 & 30 & 5,97 & 76,15 & 0 & 1,19 & I,79 & I,57 & 17,4 & 20,3 & 2,1 \\
\hline & 0 & & 6,74 & 68,29 & 0,0088 & 1,23 & 3,03 & 32,24 & 32,3 & 10,7 & 16,4 \\
\hline \multirow{6}{*}{$\begin{array}{l}\text { Sausage } \\
\text { boiled } \\
\text { Russian } \\
\text { "Milk" }\end{array}$} & 1 & 30 & 6,73 & 68,41 & 0,0086 & $|, 3|$ & 2,86 & 37,55 & 25,6 & 11,2 & 16,4 \\
\hline & 2 & ס & 6,75 & 68,30 & 0,0083 & $\mathrm{I}, 42$ & 3,24 & 36,24 & 26,3 & 10,9 & 16,3 \\
\hline & 3 & & 6,75 & 68,31 & 0,0083 & $\mathrm{I}, 49$ & 2,97 & 38,78 & 24,1 & 10,7 & 16,0 \\
\hline & 1 & & 6,36 & 68,39 & 0,0016 & $\mathrm{I}, 75$ & 39,58 & 58,17 & 34,3 & 10,6 & 15,9 \\
\hline & 2 & 180 & 6,18 & 67,88 & 0,0008 & I,83 & 24,43 & 74,31 & 33,5 & 10,3 & 16,6 \\
\hline & 3 & & 5,68 & 65,41 & 0,0001 & $\mathrm{I}, 74$ & 25,72 & 132,92 & 31,4 & 11,7 & 15,8 \\
\hline
\end{tabular}

From the data in Table 1, it can be seen that parameters such as $\mathrm{pH}$ value and moisture content depended little on the radiation dose. Changes in these values with increasing shelf life are apparently associated with general changes in the matrix of samples caused by the development of internal biochemical processes under the influence of persistent enzymatic activity. In the literature it was noted that gamma-radiation exposure leads to a significant decrease in bacterial activity. And this process is even more pronounced under the influence of gamma irradiation, in comparison with irradiation on an electron accelerator. ${ }^{1,4,10}$ However, it seems that it is not possible to completely suppress the process with the dose capacities studied. Similarly, no significant changes were observed in the total protein and fat content, recalculated to absolutely dry sample substances.
The increase in the acid number is associated with the development of both the radiolysis process and enzymatic transformations with the release of free, primarily fatty acids. This is evidenced by data on the content of volatile fatty acids. The mass fraction of them increased in all cases. The most significant was the decrease in the peroxide value. In the literature, there was a clear tendency to increase the amount of saturated fatty acids and reduce the number of polyunsaturated fatty acids in compositions based on the animal raw material of irradiated samples as compared to the unirradiated sample with increasing radiation dose. ${ }^{11}$ We can also state that in the samples we studied, the mass fraction of the limiting fatty acids increased by $2-5 \%$ of the total content. Peroxide number, as an indicator, depending on the presence, including unsaturated chemical bonds, can decrease with their decrease. 
The decrease in the content of $\mathrm{NaNO}_{2}$ added to meat products to enhance the color of the finished product is usually observed in all samples of meat products with prolonged storage. Usually this is associated with the general conversion of nitrogenous substances under microbial action. A significant reduction in the content of sufficiently toxic nitrite in production under irradiation is one of the few favorable effects of $\gamma$-radiation exposure. In our case, despite the presence of "sterilizing" irradiation, the effect of reducing the nitrite content with the growth of storage times was quite pronounced, which is apparently explained by the intensive radiolysis of nitrogen containing components. Similarly, the observed values of the aminoamino nitrogen content decreased.

Visually, the color changes stabilized by nitrite are clearly visible on unirradiated samples having a characteristic "meat" color, due to the presence of heme iron. Irradiated products with a dose of more than $1 \mathrm{kGy}$ have a grayish shade, always acquiring an unfavorable gray color with an increase in the radiation dose. ${ }^{9}$ All listed in Table 1 quality indicators are integral and characterize the total state of the studied objects with a specific composition of the components included. Using the capabilities of modern chromatomass spectrometry, it was of interest to estimate the real changes in the composition of the main components identified in the products studied. For this, model compositions based on a mixture of pork and beef were used.

In Table 2 shows the content of some fatty acids and related chemical compounds in the unirradiated and irradiated products, which could be observed in chromatographic mass spectrometric analysis. In Table 2 fatty acids and their alkyl substituted derivatives are indicated as methyl esters of fatty acids as a sum of free and fatty acids, since methylation was used in the analysis for reliable chromatographic identification in gas chromatography. In native raw materials, these substances are contained in the form of free fatty acids or in the form of residues of fatty acids.

Table 2 The content of some substances in raw and radiation-irradiated meat raw materials $(n=3)$

\begin{tabular}{|c|c|c|c|c|c|c|}
\hline \multirow{2}{*}{$* \mathbf{R T}, \mathbf{m i n}$} & \multirow{2}{*}{ Name } & \multirow{2}{*}{$* *$ CAS\# } & \multicolumn{3}{|c|}{ Content in the Irradiated Sample, $\mathrm{g} / \mathrm{l} 00 \mathrm{~g}$ fat } & \multirow{2}{*}{$\begin{array}{l}\text { Probability } \\
\text { of mass- } \\
\text { spectrometric } \\
\text { identification,\% }\end{array}$} \\
\hline & & & 0 kGy & I kGy & 6 kGy & \\
\hline 4,854 & I, I-dimethoxy-dodecane & $001599-47-9$ & 0 & $0,014 \pm 0,004$ & $0,092 \pm 0,018$ & 76 \\
\hline 6,784 & Methyl octanoate & $00011|-| I-5$ & $0,015 \pm 0,006$ & $0,042 \pm 0,011$ & $0,04 \pm 0,01$ & 68 \\
\hline 8,196 & 4,5-diphenyl-IH-I,2,3-triazole & 005533-73-3 & 0 & $0,15 \pm 0,06$ & $0,23 \pm 0,05$ & 65 \\
\hline 8,922 & Methyldecanoate & $000110-42-9$ & $0,084 \pm 0,009$ & $0,17 \pm 0,06$ & $0,26 \pm 0,07$ & 98 \\
\hline 9,612 & I, I-dimethoxyheptane & $010032-05-0$ & 0 & $0,075 \pm 0,012$ & $0,051 \pm 0,019$ & 67 \\
\hline 10,494 & Methyl-6,6-dimethoxy octanoate & 065।57-89-3 & 0 & $0,054 \pm 0,014$ & $0,06 \pm 0,01$ & 65 \\
\hline 10,702 & Methyl dodecanoate & $000111-82-0$ & $0,1 I \pm 0,03$ & $0,34 \pm 0,12$ & $0,32 \pm 0, I$ & 97 \\
\hline II,408 & $\begin{array}{l}\text { I-anthracene-9-yl-2- } \\
\text { (4-dimethylamino-phenyl) } \\
\text { ethylene }\end{array}$ & 060949-20-4 & 0 & $0,12 \pm 0,02$ & $0,06 \pm 0,02$ & 65 \\
\hline II,989 & Methyl-12-methyltridecanoate & $1000336-46-9$ & 0 & $0,022 \pm 0,007$ & $0,04 \pm 0,01$ & 96 \\
\hline 12,113 & Methyl- I I-tetradecenoate & $1000130-82-8$ & 0 & $0,026 \pm 0,008$ & $0,024 \pm 0,006$ & 75 \\
\hline $12,18 \mid$ & Methylmyristoleate & 056219-06-8 & $0,13 \pm 0,05$ & $0,62 \pm 0,17$ & $0,59 \pm 0,05$ & 99 \\
\hline$|2,29|$ & Methyltetradecanoate & $000 \mid 24-10-7$ & $4,03 \pm 0,35$ & $4,24 \pm 0,36$ & $4,65 \pm 0,45$ & 98 \\
\hline 12,720 & Methyl-13-tetradecenoate & $1000336-3 \mid-4$ & $0,06 \pm 0,01$ & $0,08 \pm 0,01$ & $0,13 \pm 0,02$ & 99 \\
\hline 14,163 & Methyl- I4-methylhexadecanoate & $002490-49-5$ & $0,44 \pm 0,09$ & $0,47 \pm 0,11$ & $0,46 \pm 0,09$ & 97 \\
\hline 14,163 & Methyl-I5-methylhexadecanoate & $1000336-34-2$ & $0,46 \pm 0,09$ & $0,43 \pm 0,08$ & $0,44 \pm 0,08$ & 94 \\
\hline 14,334 & Methyl-heptadecanoate & $00|73|-92-6$ & $1,69 \pm 0,16$ & $1,65 \pm 0,14$ & $1,58 \pm 0,15$ & 99 \\
\hline 14,853 & Methyl-9-octadecenoate & $001937-62-8$ & $31,92 \pm 1,25$ & $30,87 \pm 2,01$ & $30,11 \pm 1,98$ & 98 \\
\hline 15,019 & Methyl-6-octadecenoate & $052355-3 \mid-4$ & $3,24 \pm 1,13$ & $3,32 \pm 1,18$ & $3,06 \pm 1,11$ & 65 \\
\hline 16,011 & Methyl-I I-eicosenoate & $1000333-63-8$ & $3,66 \pm 1,22$ & $3,59 \pm 1,36$ & $3,67 \pm 1,25$ & 99 \\
\hline 16,539 & $\begin{array}{l}\text { I,I-doxy-3- (hexahydro- } \mid \mathrm{H} \text { - } \\
\text { azepin-I-yI) - I,2-benzisothiazole }\end{array}$ & $309735-29-3$ & 0 & $0,04 \pm 0,01$ & $0,17 \pm 0,04$ & 65 \\
\hline 16,882 & $\begin{array}{l}\text { Methyl-7, 10,13,16- } \\
\text { docosatetraenoate }\end{array}$ & $1000333-54-8$ & $0,21 \pm 0,04$ & $0,25 \pm 0,05$ & $0,31 \pm 0,05$ & 96 \\
\hline 17,203 & Methyldodicosanoate & 000929-77-I & $0,1 I \pm 0,02$ & $0,14 \pm 0,03$ & $0,19 \pm 0,04$ & 99 \\
\hline 18,428 & Methyltetracosanoate & $002442-49-1$ & $0,09 \pm 0,01$ & $0,12 \pm 0,02$ & $0,03 \pm 0,01$ & 98 \\
\hline 22,726 & Cholesterol & 000057-88-5 & $0,37 \pm 0,08$ & $0,35 \pm 0,06$ & $0,34 \pm 0,06$ & 95 \\
\hline
\end{tabular}

* - the characteristic time of release of the peak of the substance on the chromatogram during the analysis

** - numerical identifier of chemical compounds according to the International nomenclature 
The products of irradiation observed aromatic, including anthracene structures, which were absent in the unirradiated raw material and which, as is known, can cause oncological complications. Also in irradiated products, a certain number of isomers of fatty acids, for example, 12-methyltridecanoate, 11-tetradecenoate, etc., were observed, which are generally completely absent in animal raw materials or their quantity at the beginning of the biosynthesis of fatty acids is insignificant, such as, for example, 13-tetradecenoate. This indicates the development of the processes of conformational transformations of fatty acids, even at low doses of irradiation of $1 \mathrm{kGy}$.

In Table 2 only the main lipid components are indicated. In the list of substances identified in the irradiated samples with a dose of 1-6kGy, more than 250 additional organic compounds, including amines, amides, ketones, heterocycles and other substances, were found with a total level of their content from 0.02 to $0,5 \%$ in terms of fat. The vast majority of these substances were not found in the feedstock. Their total number was more than $18 \%$ for a sample irradiated with a dose of $1 \mathrm{kGy}$ and more than $34 \%$ for a sample subjected to irradiation with a dose of $6 \mathrm{kGy}$.

Table 2 shows the most characteristic lipid components, which underwent noticeable transformations as a result of irradiation. It should be noted that when irradiated with a dose of 1-6 kGy we observed the effect of cis-trans isomerization of unsaturated fatty acids. In the literature it is noted that when the radiation dose increases, the content of harmful trans-isomers of fatty acids in meat production increases. ${ }^{12,13}$ It is known that the content of trans-isomers in meat of farm animals is very low and is less than $0.001-0.01 \%$ of the sum of fatty acids. When stored, this indicator usually increases. ${ }^{14}$

In the studied meat samples, we observed an increase in the content of the trans-isomer of elaidic acid by more than five times from $0.01 \%$ to $0.05 \%$, which indicates the presence of a sufficiently powerful energy-physical effect. In unirradiated comparison samples, the amount of elaidic acid did not increase substantially during storage. In the meat product irradiated at maximum doses, the content of trans-elaidic acid reached $0.1 \%$ of the sum of fatty acids. Thus, the commonly used level of irradiation of products on the basis of animal raw materials with doses of more than $1 \mathrm{kGy}$ and providing conditional sterilization provides a sufficiently significant change in the chemical composition of the lipid part of the product.

\section{Conclusion}

Radiation $\gamma$-irradiation of animal raw materials and food products on its basis allows to increase the shelf life of products, but leads to changes in its chemical composition of the most important substances, contributing to the radiation-chemical transformation of the components. Further studies of the hazard or safety of such products should be conducted to obtain reliable utility data and, especially, safety for humans. The brief investigation of the effect of gamma radiation on the lipid part of the production based on animal raw materials clearly shows that the achieved change in the chemical composition of irradiated products really raises questions about whether a human needs such food products with artificially changed chemical composition.

\section{Acknowledgements}

None.

\section{Conflict of interest}

The author declares no conflict of interest.

\section{References}

1. Isamov NN, Sanzharova NI, Kobyalko VO, et al. Application of radiation technologies to ensure the safety of products of animal origin. All About Meat (Russ). 2017;1:11-15.

2. Drozdova NA, Dydykin AS, Gorbunova NA, et al. Application of ionizing and non-ionizing radiation in the food industry. All about meat (Russ). 2017;1:16-19.

3. Gelfand SYu, Petrov AN, Filippovich VP, et al. Modern aspects of radiation treatment of food products. Food processing industry (Russ). $2013 ; 2: 25-31$

4. Gorbunova NA. Perspectives of application of technology of ionizing irradiation of meat and meat products. Meat industry. 2016;9:21-23.

5. Directive 1999/2/CE of the European Parliament and of the Council of 22 February 1999 on the approximation of the laws of the United States of America in relation to food and food ingredients treated with ionising radiation. Europe: EUR-Lex; 1999.

6. Flamm G, Burdock G, Forbes A, et al. Safety and nutritional adequacy of irradiated food. Geneva: World Health Organization; 1999.

7. Kulikovsky AV, Vostrikova NL, Gorbunova NA, et al. Identification of accumulation of chemical markers of irradiation in biomatrices with ionizing processing of meat raw materials. All About Meat (Russ). 2017;1:21-25.

8. Lisitsyn AB, Ivankin AN, Neklyudov AD. Methods of practical biotechnology. Moscow, USA: VNIIMP Publ; 2002

9. Ivankin AN, Vostrikova NL, Kulikovsky AV, et al. Radiation treatment of food products based on meat raw materials. Meat Industry. 2017;11:32-35.

10. Park JG1, Yoon Y, Park JN, et al. Effects of gamma irradiation and electron beam irradiation on quality, sensory, and bacterial populations in beef sausage patties. Meat Sci. 2010;85(2):368-372.

11. Rayna Stefanova, Stoyan Toshkov, Nikola V Vasilev, et al. Effect of gamma-ray irradiation on the fatty acid profile of irradiated beef meat. Food Chemistry. 2011;127(2):461-466.

12. Ismail Yilmaz, Umit Geçgel. Effects of gamma irradiation on trans fatty acid composition in ground beef. Food Control. 2007;18(6):635-638.

13. Alfaia Cristina MM, Ribeiro Paulo JL, Castro Matilde LF, et al. Gamma irradiation effect on fatty acid composition and conjugated linoleic acid isomers of lamb meat. Meat science. 2007;77:689-695.

14. Ivankin AN, Semenova AA, Nasonova VV, et al. Biotechnology for formation of aromatic properties of national- foodstuffs on the basis of meat raw material under influence of bacterial crops and chromato-mass-spectrometric analysis of the flavoring components. $J$ Appl Biotechnol Bioeng. 2017;3(4):00072. 